ostrich-like policy is that the great majority of cancers are not fit for operation when first seen by the medical adviser, and that many more are on the border-line, and the operation is performed with but a dubious hope that it may be in time. The public need to be taught carefully and simply, as Mr. Childe teaches in "The Control of a Scourge." They need to learn the importance of early advice, the good hope of early operation, and the folly of delay in these cases-for delay means death.

Mary Scharlieb, M.S.

\title{
MEDICINE AND THE PUBLIC. 1
}

Dr. Sprigge's book is a most valuable and instructive work for the layman, now that appreciation of the true mission of the medical profession is prevalent among the more intelligent classes. The development of Preventive Medicine and the Department of Public Health have raised a greater community of interest between the profession and the people, which makes this book of especial interest. Writing as a layman who has had, during the last thirty years, some acquaintance with men and matters medical, and as one who has had the advantage of a pre-perusal of some of the articles when they appeared in the Lancet, I have been particularly attracted by the chapters upon Medical Education. There is nothing more important than the training of young medicine in the light of present-day conditions, and the discussion in other chapters of the proposals for a Ministry of Public Health, of the management and support of the hospitals, of professional etiquette, and of the public conception of the duties of medical men, is one which cannot fail to interest all who read this book. The consideration of the relationship between the general practitioner and the "consultant" is exceedingly important, and the foreshadowing of imperial sanitary, Poor Law, naval, military, and colonial medical services is very suggestive. The author says: "If the first step towards the reform of the admitted abuses of the medical profession is the establishment of solidarity among medical men, the second is the establishment of confidence between the medical profession and the public. When these two consummations exist, reform will be imminent." I can only say that a study of this book would very materially expedite that end. JoHn TURner RaE.

\section{ELEMENTS OF COMPARATIVE MEDICINE. ${ }^{2}$}

The authors" aim is "to give an outline of the principal clinical features of some of the diseases that are communicable from the lower to the higher creation."

The section dealing with tuberculosis evidences want of care and lack of judgment. We read, "The bacillus when stained is seen to be beaded, owing to the presence of spores"-a view not generally accepted by the best pathologists. Again, we are told that the staining reaction of the Bacillus twbevculosis differs from that of all other bacteria save leprosy, no mention being made of the smegma bacillus

1 "Medicine and the Public," by S. Squire Sprigge, M.A., M.D. (Cantab.). London: Heinemann. $6 \mathrm{~s}$. net.

2 "The Elements of the Practice of Comparative Medicine." By F. T. Barton, M.R.C.V.S., and G. Gresswell, M.A., L.R.C.P., L.R.C.S., L.F.P.S. Pp. 240. London: Everett and Co. 1906. 


\section{I82 THE BRITISH JOURNAL OF TUBERCULOSIS}

and of the saprophytic bacilli found on grasses. It is stated on reliable authority elsewhere that some thirty different organisms all behave like the $B$. tuberculosis in its staining reactions with aniline dyes. The statement that women are more frequently affected by tubercle than men is contrary to what is usually stated by most competent observers. We are surprised, too, that the authors do not mention the agglutination test in the differential diagnosis of typhoid fever and acute miliary tuberculosis, and also that they do not point out how uncommon are diarrhoa and tympanites in generalized tuberculosis.

Other sections are equally faulty, and the nomenclature of the authors is often undesirable, as, for instance, where they speak of cutaneous anthrax as "malignant pustule," a term now generally condemned.

The book certainly directs the attention of students to diseases which have received far too little notice in the past, as is demonstrated by the reports of some cases, which are very interesting. With the expenditure of a little more care the work might have been made of real service. W. G. Kinton, M.B.

\section{THE WELFARE OF THE SCHOOL-CHILD. ${ }^{1}$}

Dr. Leslie Mackenzie has issued a very useful and suggestive little book dealing largely with methods of school inspection in Germany, where, of course, medical oversight is much more thorough and systematic than in this country. Indeed, it is probably carried, as Dr. Mackenzie suggests, somewhat beyond reasonable limits. "Every fortnight, and more frequently if infectious diseases are prevalent, the school doctor holds a consultation at the school with the school director on a day previously arranged." As the number of scholars in each school is from 1,000 to $I, 500$, this must involve no little expenditure of time and trouble; but there can be no doubt that some such system enforced in our public elementary schools would be of immense service to the nation. One of the most important papers in this volume is that entitled" Medical Examination and Supervision of Schools and SchoolChildren," in which there is a great deal of very good advice. It should be studied by teachers, without whose intelligent and sympathetic co-operation any system of medical examination is likely to prove inadequate. This section-and, indeed, the whole book--might well be placed in the hands of all teachers. Arthur E. Gregory.

\section{SCHOOL HYGIENE. ${ }^{2}$}

Dr. Charles Porter's manual, which is the outcome of a course of lectures to teachers, strives not only to inculcate the principles of hygiene and the laws of health, but to give the ground-work on which these are based. It contains a great deal of physiology, a little medicine, some bacteriology, and a useful smattering of other sciences. After a detailed account of the physiology of each organ the author

1 "The Health of the School-Child." By W. Leslie Mackenzie, M.A., M.D., D.P.H., M.R.C.P.E., F.R.S.E. London: Methuen and Co. Pp. r2o. rgo6. Price 2s. 6d.

2 "School Hygiene and the Laws of Health." By Charles Porter, M.D., B.Sc., M.R.C.P.E. Pp. 3I3. With II9 Illustrations. London : Longmans, Green and Co. Igo6. Price 3s.6d. 